\title{
Psychological disorders in rheumatoid arthritis: A growing consensus?
}

\author{
Francis Creed
}

\begin{abstract}
Previous reviews of psychological factors in arthritis have emphasised the methodological weaknesses of many studies, especially those attempting to measure personality after years of disabling disease. To make sense of the published reports three factors need to be considered separately: previous personality, social stresses, and current mental state. Each can now be measured reliably and independently of symptoms which might be directly attributable to the arthritis. There is a growing consensus that the normal range of personality is represented among patients with early arthritis, that the prevalence of depression is similar to that of patients with other medical conditions, and that social stress is more closely related to depression than activity and the disabling effect of arthritis. Longitudinal studies are now required to examine which social stresses can be attributed to the disabling effect of arthritis. Depression and social stress often manifest themselves to the rheumatologist as excessive complaints of pain and frequent clinic attendances so appropriate psychosocial treatments may reduce this behaviour.
\end{abstract}

The importance of psychological factors in rheumatoid arthritis (RA) has been stressed in numerous publications. Early views focused on the 'rheumatoid personality' and psychological stress as primary causes, ${ }^{1-4}$ but most personality and relationship difficulties are best regarded as the result of chronic disabling disease and not its cause. ${ }^{5}$ A recent review has once again indicated the importance of stress as a cause, ${ }^{6}$ but in line with all previous reviewers the authors were sharply critical of much of the research to date. Anderson et al concluded that only after more precise studies have provided a full understanding of the role of psychological factors in RA can these be used to improve patient care. ${ }^{6}$

Since the Anderson review a number of studies have been published which have used improved methodology so it is now appropriate to reasssess the role of psychological disorders

Psychiatry,

Manchester Royal

Infirmary, Oxford Road,

Manchester M13 9WL

F Creed

Accepted for publication

22 February 1990

Psychological variables to be measured Measures have been used in three areas of in rheumatoid arthritis.

psychosocial functioning-personality, current mental state, and current social stresses (fig 1).

\section{PERSONALITY}

The term personality refers to habitual responses and coping mechanisms that are stable over time and which are considered to arise from genetic factors and early environmental experiences, such as loss of a parent or exposure to abnormal parental attitudes. Aspects of the personality relevant to chronic illness include the tendency towards self reliance versus dependence on others, general attitudes towards illness and health, and the characteristic response to stress. Such attributes will exist before the start of a chronic illness but may determine the pattern of disability that arises later.

Personality is measured by such instruments as the Minnesota multiphasic personality inventory $(M M P I)^{7}$ and the Eysenck personality inventory, ${ }^{8}$ but the results of these questionnaires can change with chronic illness so it becomes impossible to obtain a reliable estimate of pre-existing personality once a chronic, disabling disorder has become established.

\section{CURRENT MENTAL STATE}

Anxiety and depression will be terms used throughout this paper to denote abnormalities in current mental state. Because the symptoms of anxiety neurosis and depressive illness overlap the term 'depression' will be used hereafter to denote a state of mixed anxiety and depression.

An estimate of the degree of depression can be obtained by using self-administered questionnaires such as the Middlesex Hospital questionnaire, ${ }^{9}$ the general health questionnaire, ${ }^{10}$ the hospital anxiety and depression scale, ${ }^{11}$ the Zung depression scale, ${ }^{12}$ and the Beck depression inventory. ${ }^{13} \mathrm{~A}$ diagnosis of anxiety or depression sufficiently accurate for research purposes can only be obtained when a trained psychiatrist uses a standardised interview, however. Examples are the clinical interview schedule, ${ }^{14}$ the diagnostic interview schedule, ${ }^{15}$ and the psychiatric assessment schedule, ${ }^{16}$ which all assess symptoms of anxiety and depression at a standardised interview. Each symptom is only recorded if it meets a precise criterion of severity-for example, loss of one or 


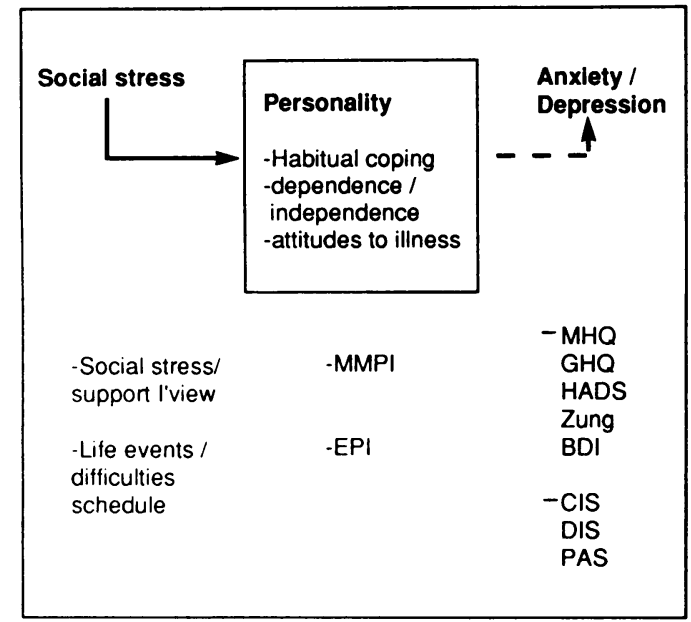

Figure I Illustration of three psychosocial variables (above) and instruments used to measure each (below). $M M P I=$ Minnesota multiphasic personality inventory ${ }^{7}$; $E P I=$ Eysenck personality inventory ${ }^{8} ; M H Q=$ Middlesex Hospital questionnaire ${ }^{9} ; G Q=$ general health questionnaire ${ }^{10} ; H A D S=$ hospital anxiety and depression scale $^{I I} ;$ Zung $=$ Zung depression scale ${ }^{I 2} ; B D I=B e c k$ depression inventory ${ }^{23} ; C I S=$ clinical interview schedule $^{14}$; $D I S=$ diagnostic interview schedule $^{I 5} ; P A S=$ psychiatric assessment schedule. ${ }^{16}$

month, or clear panic attacks on five or more occasions in the last month. The number and type of such symptoms are then used to decide if the subject fulfils the criteria of a 'case' of psychiatric disorder.

\section{SOCIAL STRESS}

The third area of measurement concerns current social stresses. These may be measured by the social stress and support interview ${ }^{17}$ or by a measure of life events and difficulties (Brown and Harris). ${ }^{18}$ In either interview the subject is asked about current problems with housing, finance, occupation, family, marital and sexual relationships. Careful research should try to take into account those social difficulties that arise directly from the RA-for example, inability to work, and those which are independent-for example, husband's chronic ill health.

\section{Personality in RA}

Many early studies using the MMPI were misinterpreted until longitudinal studies showed that early in the disease the personality of patients with RA is no different from that in the normal population. ${ }^{19} 20$ The changes that occur in the MMPI with chronic RA are accounted for by the 'disease related' items ${ }^{21}:$ I am about as able to work as I ever was; I am in just as good physical health as most of my friends; during the past few years I have been well most of the time; I do not tire quickly; I have few or no pains. Such items are scored on the MMPI as indicative of depression and hypochondriasis. In fact they may be directly attributable to the disability which occurs in rheumatoid arthritis. When these items were excluded the personality of patients with $R A$ was found to be no different from that of the general population. ${ }^{21}$

Thus the full range of personalities will be represented early in $\mathrm{RA}$; some of these will adapt well to the disease, whereas others, such as women excessively prone to anxiety located by the Middlesex Hospital questionnaire, ${ }^{9}$ are likely to react poorly to increasing physical disability.

\section{Prevalence of anxiety and depression}

Rimon quoted figures for the prevalence of depression in RA between 22 and $80 \%^{22}$; the range in recent studies is somewhat narrower (table 1). Questionnaire studies have produced widely discrepant figures, which are generally higher than the interview studies. Two of the latter included sample sizes too small for reliable results, ${ }^{27} 28$ and thus only two studies used widely accepted criteria and these gave somewhat similar results. ${ }^{15} 30$

Three studies looked specifically to see whether the symptoms of appetite, sleep, and energy might distort the prevalence of depression. Bishop et al found that the somatic items on the Beck depression inventory correlated well with the total depression scores and did not correlate with RA activity so they concluded that their figure of $19 \%$ prevalence was accurate. ${ }^{25}$ Murphy et al also found that exclusion of the somatic items from the psychiatric assessment schedule interview scores did not alter the overall prevalence figure of $21 \%{ }^{30}$

Table 1 Prevalence of anxiety/depression in rheumatoid arthritis

\begin{tabular}{|c|c|c|c|c|c|}
\hline Author & Instrument* & $\begin{array}{l}\text { Subj } \\
(n)\end{array}$ & ects & $\begin{array}{l}\text { Prevale } \\
(\%)\end{array}$ & \\
\hline $\begin{array}{l}\text { Self-administered questionnaires } \\
\text { Zaphiropoulos and Burry }{ }^{23}\end{array}$ & BDI & 50 & Inpatients & \multirow{2}{*}{$\begin{array}{l}\text { Adm } \dagger \\
\text { Disch } \dagger \\
\text { Disch } \\
\text { Adm }\end{array}$} & \multirow{2}{*}{$\begin{array}{l}46 \\
23 \\
53 \cdot 5 \\
19 \\
32 \\
28\end{array}$} \\
\hline $\begin{array}{l}\text { Gardiner }{ }^{24} \\
\text { Bishop et } a l^{25} \\
\text { Chandarana et } a l^{26} \\
\text { Chandarana et } a l^{26}\end{array}$ & $\begin{array}{l}\text { GHQ } \\
\text { BDI } \\
\text { GHQ } \\
\text { HADS }\end{array}$ & $\begin{array}{r}129 \\
39 \\
86 \\
86\end{array}$ & $\begin{array}{l}\text { Inpatients } \\
\text { Inpatients } \\
\text { Outpatients } \\
\text { Outpatients }\end{array}$ & & \\
\hline $\begin{array}{l}\text { Clinical interviews } \\
\text { Hudson et } a l^{27} \\
\text { Mindham et } a l^{28}\end{array}$ & $\begin{array}{l}\text { DIS } \\
\text { CIS }\end{array}$ & $\begin{array}{l}14 \\
28\end{array}$ & $\begin{array}{l}\text { Outpatients } \\
\text { Outpatients }\end{array}$ & \multirow{2}{*}{\multicolumn{2}{|c|}{ 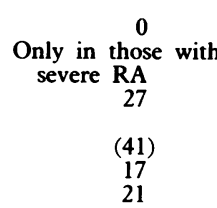 }} \\
\hline $\begin{array}{l}\text { Rimon and Laakso } 29 \\
\text { Frank et al }\end{array}$ & $\begin{array}{l}\text { Clinical interview } \\
\text { DIS } \\
\text { PAS }\end{array}$ & $\begin{array}{r}74 \\
137 \\
80\end{array}$ & $\begin{array}{l}\text { Outpatients } \\
\text { Outpatients: } \\
\text { (Dysthymic disorder) } \\
\text { Major depressive disorder } \\
\text { In/Outpatients }\end{array}$ & & \\
\hline
\end{tabular}


Frank et $a l^{15}$ considered the figure (17\%) for major depressive disorder to be more accurate than that for dysthymic disorder $(41 \%)$ as the symptoms of the latter (a chronic dissatisfaction fluctuating over the previous two years ${ }^{29}$ ) overlap greatly with those of RA. The criteria for major depressive disorder ${ }^{31}$ also include somatic symptoms so the prevalence figures may therefore still be too high (34\% for women and $12 \%$ for men). When the Murphy data were reanalysed using similar criteria the prevalence was $24 \%$ in a predominantly female sample. ${ }^{32}$

In summary, the interview figures range from $21 \%$ to $34 \%$ and the three recent studies all concluded that the prevalence of depression in RA is similar to that of patients with other chronic diseases. ${ }^{153033}$

\section{Correlation with severity of arthritis}

It has generally been accepted that the more disabling the disease the higher the prevalence of depression. ${ }^{34}$ Evidence for this view came from studies indicating that increasingly severe rheumatological disease was associated with increasing depression 2028 and hospital treatment for RA was associated with improvement in depression. ${ }^{23} 25$

Questionnaire studies have provided conflicting results on this issue; Chandarana et al found that depression scores were positively correlated with pain, duration of morning stiffness, and functional capacity. ${ }^{26}$ On the other hand, two studies used the more specific Beck depression inventory ${ }^{23}{ }^{25}$ and were unable to find significant associations between degree of depression and duration or severity of the arthritis.

McFarlane and Brooks also found no significant correlation between total symptom score using the Middlesex Hospital questionnaire with any measure of disease activity, disability, or the duration of the illness. ${ }^{35}$ The only significant correlations were those between the somatic subscale of the Middlesex Hospital questionnaire (tiredness, sleep, appetite, indigestion, sexual interest) and total disease severity and pain scores, indicating once more the importance of measuring psychiatric state independently of somatic symptoms.

Research interviews should provide more reliable results. In the study by Frank et al mentioned above depressed patients reported more pain, but there was no significant association with erythrocyte sedimentation rate, total joint score, walking time, grip strength, or duration of morning stiffness. ${ }^{15}$ The more stringent criteria used by Murphy et al ensured that depression was measured independently of symptoms attributable to arthritis. It was found that psychiatric disorder was not related to 10 measures of activity and duration of RA. The only two measures which were significantly different in those with depression were grip strength and the health assessment questionnaire index. ${ }^{30}$

As these are cross-sectional studies significant correlations tell us nothing about causality; pain, reduced grip strength, and increased disability might equally well be the result of depression as related to its cause.

\section{Longitudinal studies}

Only one study has repeatedly interviewed patients in a longitudinal study. ${ }^{28}$ There were only 28 patients and marked depression was very rare, occurring only in those few patients who had active and seriously disabling rheumatoid arthritis. Another longitudinal study used repeated administrations of the Beck depression inventory and also found increased depression at times of acute flare-ups leading to hospital admission. ${ }^{25}$ Neither study found a correlation between levels of depression and weekly or monthly fluctuations in RA activity, however, which would be expected if RA activity was directly linked to depression.

Two recent longitudinal studies used a different design, making detailed assessment three years apart and evaluating which features at initial assessment predicted depression at follow up. ${ }^{33}$ In one study disease activity decreased, while both disability and depression increased during the three years, but there were no significant relationships between increase in depression and any of the measures of disease activity and disability (Ritchie articular index, pain score, duration of morning stiffness, proximal interphalangeal joint circumference, activities of daily living index). ${ }^{35}$ In the other study worsening depression was not associated with any of the following: grip strength, joint count, pain, disability (health assessment questionnaire). ${ }^{33}$ The factors which did emerge as significant in a regression analysis which controlled for initial levels of depression were age, education level, marital status, family income. The authors concluded that demographic and social data, but not clinical characteristics, distinguished the depressed and nondepressed groups.

Other multivariate studies have used crosssectional data rather than longitudinal data to examine more closely the factors which predict depression. The results are shown in table 2, and it can be seen that in two studies ${ }^{15} 33$ only about $20 \%$ of the variance was accounted for, leaving the largest part unexplained. Frank et al suggested that further variance would be explained by the patient's early experience, constitutional liability to develop depressive illness, current life stresses, and social status. Indeed, the study of Creed et al confirmed that the variables 'social stress' and 'lack of social support' greatly increased the variance explained by disease factors alone. ${ }^{32}$

The report of Newman et al concerned a score on the Beck depression inventory not a clinical interview but took care to exclude somatic symptoms of depression. ${ }^{36}$ Their results support Rimon's assertion that depression in RA might result from either disabling arthritis or an emotionally traumatic life event. ${ }^{29}$ Examples of the latter observed by Rimon included death of a close family member, marital infidelity or severe alcohol abuse by the spouse. ${ }^{29}$

\section{Social stress}

There have been few systematic studies of social stress in arthritic patients. Although many occupational and financial problems are the 
Table 2 Multivariate analyses to predict psychiatric disorder

\begin{tabular}{|c|c|c|}
\hline Author & Factor & $\%$ Variance explained \\
\hline Hawley $e t a l^{33}$ & $\left.\begin{array}{l}\text { Pain } \\
\text { HAQ* disability } \\
\text { Age } \\
\text { Family income } \\
\text { Joint count }\end{array}\right\}$ & 25 \\
\hline Frank et $a l^{15}$ & $\begin{array}{l}\text { Pain adjectives (MPQ)* } \\
\text { Erythrocyte sedimentation rate } \\
\text { Pain description as 'numbness' } \\
\text { Satisfaction with current lifestyle }\end{array}$ & 20 \\
\hline Creed $e t a l^{32}$ & $\left.\begin{array}{l}\text { Grip strength } \\
\text { HAQ } \\
\text { Social stress }\end{array}\right\}$ & 74 \\
\hline Win & $\begin{array}{l}\text { Demographic (female sex) } \\
\text { Effect of disease and disability } \\
\text { Disease duration } \\
\text { Social isolation } \\
\text { Economic deprivation }\end{array}$ & 44 \\
\hline
\end{tabular}

${ }^{*} \mathrm{HAQ}=$ health assessment questionnaire; $\mathrm{MPQ}=\mathrm{McG}$ ill pain questionnaire.

result of disabling $\mathrm{RA}^{5}$ unstable marital relationships may, of course, also occur independently of the disease. ${ }^{37}$ The social factors related to depression in patients with RA have been assessed with imprecise variables such as 'low family income' and 'dissatisfaction with current lifestyle' (table 2), but two recent systematic studies have been performed.

In one study 'social stress' and 'lack of social support' were measured separately. ${ }^{30}$ Both factors were significantly related to the presence of depression, but the stress factors of financial problems, social contacts, and marital problems were significantly related to duration of $R A$, indicating a possible relation with disability. Further longitudinal studies are required to examine this possibility. 'Lack of support' was not related to duration or severity of RA, suggesting a direct correlation with depression as observed by $\operatorname{Rimon}^{29}$ and concurring with studies of depression in the community. ${ }^{18}$

In the second study a detailed analysis of social relationships in RA indicated that availability and perceived adequacy of close (family) relationships were scored similarly to those of the general population but the available wider social network (friends and neighbours) was reduced. ${ }^{38}$ This reduction correlated significantly with both the Beck depression scores and the health assessment questionnaire disability scores, and the authors suggested that reduced functional ability led to reduced social relationships, which in turn led to increased depression.

Probably, taking these two studies together, stress in the form of marital problems may lead to depression unless the woman has good support from other family members or neighbours. ${ }^{18}$ Such wider support is less likely to be available to the women with severe disabling RA. Removal from a difficult home situation may be one reason why Bishop found that depression improved while the patient was in hospital but rapidly relapsed after discharge. ${ }^{25}$ Rogers et al described a depressed patient with RA whose husband's abuse led to an exacerbation of joint symptoms and her retreat to bed produced a marked increase in her disability. ${ }^{39}$ A patient's reluctance to return home, perhaps manifesting as an exacerbation of joint symptoms when discharge is proposed, will alert the astute clinician to this type of social stress.

\section{Illness behaviour}

The practical importance of anxiety and depression and social stress is seen in two ways. Hawley and Wolfe noted during their three year prospective study that those patients who were anxious or depressed had significantly more frequent clinic attendances, which seemed to be unrelated to the severity of the arthritis. ${ }^{33}$ Thus the demand for care from the rheumatologist is likely to be greater among those with anxiety/ depression.

Secondly, but related to the first, is the patients' experience of pain and view of their illness. Frank et al noted that depressed patients are likely to use elaborate descriptions of their pain and express their dissatisfaction to the doctor, who should thereby be alerted of the need to assess the depression thoroughly. ${ }^{15}$

Parker et al found that pain severity was significantly related to functional disability, age, income, and stresses in daily life but not to erythrocyte sedimentation rate, anatomical stage, disease duration, and the swelling score from a joint count. ${ }^{40}$ The authors concluded that the patient at high risk for pain was middle aged, living on limited income, and experiencing major stresses in every day life. These patients were also prone to worry and felt isolated and lacking in social support.

These two factors, excessive complaints of pain and numerous clinic attendances unexplained by severity of RA, would now come under the description of abnormal illness behaviour. ${ }^{41}$ This can be measured by the illness behaviour questionnaire. ${ }^{42}$ Two studies have confirmed that patients with RA who were depressed were those who worried a great deal about their illness (hypochondriasis) and were convinced that it was very severe (disease conviction). ${ }^{30}{ }^{35}$ Thus the patients who complain most of pain and are excessively concerned about their illness are not necessarily those who have the most active and disabling disease but are those who have anxiety and depression and who lack social support.

It was noted above that a correlation between grip strength and depression told us nothing about causality. The relation was explored in Murphy's study, however, using regression analysis to see whether reduced grip strength was more closely related to severity of arthritis or to psychiatric disorder. ${ }^{30}$ It was found that both joint disease in RA and reduced pain threshold (or decreased motivation) in depression may lead to reduced grip strength. Thus the improvement in grip strength with antidepressants ${ }^{43}$ may in part be a direct analgesic effect $^{44}$ and in part due to improvement in mood. ${ }^{45}$ Figure 2 illustrates a possible sequence of events.

\section{Conclusion}

When psychiatric disorder is measured satisfactorily independent of severity of arthritis the prevalence is about $20 \%$, which is similar to that 
Figure 2 Interactions between psychosocial variables, disability arising from rheumatoid arthritis, and illness behaviours.

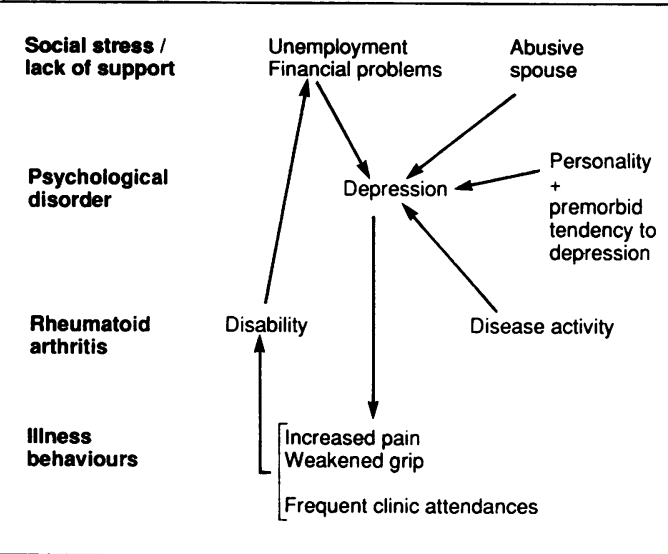

in patients with other medical conditions. The presence of anxiety and depression is not directly related to the activity and disabling effect of arthritis in most studies but does reflect lack of social support and experience of social stress. The significant relation between depression and pain/disability requires further clarification but there is probably a direct relation in which deterioration in one leads to deterioration in the other.

The importance of depression to the clinician lies in its relation to increased complaints of pain, increased concern and worry about the disease with more frequent clinic attendances, increased functional incapacity, and, possibly, reduced grip strength. The first step in correct management is recognition of anxiety and depression so that appropriate treatment can be tried. This may take the form of antidepressants, ${ }^{43}{ }^{45}$ or psychological treatment, ${ }^{46}$ but particular attention may have to be paid to social stress and lack of social support. Preliminary evidence suggests that subjective pain, observed pain behaviours, and grip strength may all be helped by such treatments. ${ }^{43} 4546$ If further studies show these advantages they should become a routine aspect of rheumatological care.

I thank Mrs Joan Bond for help in typing this manuscript.

King $\mathbf{S} \mathbf{H}$. Psychosocial factors associated with rheumatoid arthritis. F Chronic Dis 1955; 2: 287-302.

2 Moos R H. Personality factors associated with rheumatoid rthritis: a review. $\mathcal{F}$ Chronic Dis 1964; 17: 41-55.

3 Meyerowitz S. The continuing investigation of psychosocial variables in rheumatoid arthritis. In: Hill A G, ed. Modern rends in rheumatology. Vol 2. 2nd ed. London: Butterworth 1970: 92-105.

4 Hoffman A L. Psychological factors associated with rheumatoid arthritis. Nurs Res 1974; 23: 218-34.

5 Baum J. A review of the psychological aspects of rheumatic diseases. Semin Arthritis Rheum 1982; 11: 352-61.

6 Anderson K O, Bradley L A, Young L D, McDaniel L K. Rheumatoid arthritis: review of psychological factors related etiology, effects and treatment. Psychol Bull 1985; 98 : 358-87.

7 Dahlstrom W G, Welsh G S. An MMPI handbook: a guide to use in clinical practice and research. Minneapolis: University of Minnesota Press, 1960.

8 Eysenck H J. Eysenck S B G. Manual of the Eysench personality inventory. London: University of London Press, 1964.

9 Crown S, Crisp A H. A short clinical diagnostic self rating scale for psychoneurotic patients. Br $\mathcal{F}$ Psychiatry 1966 ; 112: 917-32.

10 Goldberg D. Manual of the general health questionnaire. Windsor, England: NFER-Nelson, 1978.

11 Zigmond A S, Snaith R P. The hospital anxiety and depression scale. Acta Psychiatr Scand 1983; 67: 361-70.

12 Zung W. A self-rating depression scale. Arch Gen Psychiatry 1985; 12: 63-70.
13 Beck A T, Ward C H, Mendelson M, Mock J, Erbaugh J. An inventory for measuring depression. Arch Gen Psychiatry 1961 ; 4: 561-71.

14 Goldberg D P, Cooper B, Eastwood M R, Kedward H B, Shepherd $M$. A standardised psychiatric interview for use in community surveys. British foumal of Preventive and in community surveys. British

15 Frank R G, Beck N C, Parker J C, et al. Depression in rheumatoid arthritis. $\mathcal{F}$ Rheumatol 1988; 15: 920-5.

16 Dean C, Surtees P, Sashidharan S. Comparisons of research diagnostic systems in an Edinburgh community sample. $B$ f Psychiatry 1983; 142: 247-56.

17 Jenkins R, Mann A H, Belsey E. The background, design and use of a short interview to assess social stress and support in research and clinical settings. Soc Sci Med 1981 15: 195-203.

18 Brown G W, Harris T. A study of depression in women. London: Tavistock, 1978 .

19 Robinson H, Kirk R F, Frye R L, Robertson J T. A psychological study of patients with rheumatoid arthritis and other painful diseases. I Psychosom Res 1972;16:53-6.

20 Crown S, Crown J M, Fleming J M. Aspects of the psychology and epidemiology of rheumatoid disease Psychol Med 1975; 5: 291-9.

21 Pincus T, Callahan L F, Bradley L A, Vaughn W K, Wolfe F. Elevated MMPI scores for hypochondriasis depression and hysteria in patients with rheumatoid arthritis reflect disease rather than psychological status. Arthritis Rheum 1986; 29: 1456-66.

22 Rimon R. Depression in bei chronischer Polyarthritis. Aktuelle Rheumatologie 1978; 3: 143-7.

23 Zaphiropoulos G, Burry H C. Depression in rheumatoid disease. Ann Rheum Dis 1974; 33: 132-5.

24 Gardiner B M Psychological aspects of rheumatoid arthritis. Psychol Med 1980; 10: 159-63.

25 Bishop D, Green A, Cantor S, Torresin W. Depression, anxiety and rheumatoid arthritis activity. Clin Exp Rheumatol 1987; 5: 147-50.

26 Chandarana P C, Eals M, Steingart A B, Bellamy N, Allen S The detection of psychiatric morbidity and associated factors in patients with rheumatoid arthritis. Can $\mathcal{J}$ Psychiatry 1987; 32: 356-61.

27 Hudson J I, Hudson M S, Pliner L F, Goldenberg D L, Pope H G. Fibromyalgia and major affective disorder: a controlled phenomenology and family history study. Am $\mathcal{F}$ Psychiatry 1985; 142: 441-6.

28 Mindham R H S, Bagshaw A, James S A, Swannell A J. Factors associated with the appearance of psychiatric symptoms in rheumatoid arthritis. 7 Psychsom Res 1981; 25: 429-35.

29 Rimon R, Laakso R L. Overt psychopathology in rheumatoid arthritis. A fifteen year follow-up study. Scand $\mathcal{F}$ Rheumatol 1984; 13: 324-8

30 Murphy S, Creed F, Jayson M I V. Psychiatric disorder and illness behaviour in rheumatoid arthritis. $\mathrm{Br} \mathcal{F}$ Rheumatol 1988; 27: 357-63.

31 American Psychiatric Association committee on nomenclature and statistics. Diagnostic and statistical manual of mental disorders. 3rd ed. Washington: American Psychiatric Association, 1980.

32 Creed F, Murphy S, Jayson M I V. Measurement of psychological disorders in RA. $\mathcal{F}$ Psychosom Res 1989; 34: 79-87.

33 Hawley D J, Wolfe F. Anxiety and depression in patients with rheumatoid arthritis: a prospective study of 400 with rheumatoid arthritis: a prospecti

34 Moos R H, Solomon G F. Personality correlations of the rapidity of progression of rheumatoid arthritis. Ann Rheum Dis 1964; 23: 145-5

35 McFarlane A C, Brooks P M. An analysis of the relationship between psychological morbidity and disease activity in rheumatoid arthritis. F Rheumatol 1988; 15: 926-31.

36 Newman S P, Fitzpatrick R, Lamb R, Shipley M. The origins of depressed mood in rheumatoid arthritis. I Rheumatol 1989; 16: 740-4.

37 Wright V, Owen S. The effect of rheumatoid arthritis on the social situation of housewives. Rheumatology and Rehabilitation 1976; 15: 156-60.

38 Fitzpatrick $R$, Newman S, Lamb $R$, Shipley M. Social relationships and psychological well-being in rheumatoid relationships and psychological well-being
arthritis. Soc Sci Med 1988; 27: 399-403.

39 Rogers M P, Reich P, Kelly M J, Liang M H. Psychiatric consulation among hospitalized arthritis patients. Gen consultation among hospitalized
Hosp Psychiatry 1980; 2: 89-94.

40 Parker J, Frank R, Beck N, et al. Pain in rheumatoid arthritis: relationship to demographic, medical and psychoogical factors. I Rheumatol 1988; 15: 433-7.

41 Pilowsky I. A general classification of abnormal illnes behaviours. Br J Med Psychol 1978; 51: 131-7.

42 Pilowsky I, Spence N D. Patterns of illness behaviour in patients with intractable pain. $\mathcal{F}$ Psychosom Res 1975; 19: 279-87.

43 Fowler P D, MacNeill A, Spencer D, Robinson E T, Dick W C. Imipramine rheumatoid arthritis and rheumatoid factor. Curr Med Res Opin 1977; 5: 241-6.

44 Feineman C. Pain relief by antidepressants: possible modes of action. Pain 1985; 23: 1-8.

45 Puttini S, Cazzola M, Boccassini L, et al. A comparison of dothiepin versus placebo in the treatment of pain in dothiepin versus placebo in the treatment of pain in depression. F Int Med Res 1988; 16: 331-7.

46 Bradley L A, Young L D, Anderson K O, et al. Effects of psychological therapy on pain behaviour of rheumatoid psychological therapy on pain behaviour of rheum.
arthritis patients. Arthritis Rheum 1987; 30: 1105-14. 